\title{
Complex Dynamics and Chaos Control on a Kind of Bertrand Duopoly Game Model considering R\&D Activities
}

\author{
Hongliang Tu, ${ }^{1}$ Xueli Zhan, ${ }^{2}$ and Xiaobing Mao' \\ ${ }^{1}$ School of Information and Management, Jiangxi University of Finance and Economics, Nanchang 330013, China \\ ${ }^{2}$ School of Economics, Beijing Wuzi University, Beijing 101149, China \\ Correspondence should be addressed to Xueli Zhan; xuelz20163205@126.com
}

Received 10 April 2017; Revised 29 June 2017; Accepted 12 July 2017; Published 22 October 2017

Academic Editor: Abdelalim Elsadany

Copyright (c) 2017 Hongliang Tu et al. This is an open access article distributed under the Creative Commons Attribution License, which permits unrestricted use, distribution, and reproduction in any medium, provided the original work is properly cited.

\begin{abstract}
We study a dynamic research and development two-stage input competition game model in the Bertrand duopoly oligopoly market with spillover effects on cost reduction. We investigate the stability of the Nash equilibrium point and local stable conditions and stability region of the Nash equilibrium point by the bifurcation theory. The complex dynamic behaviors of the system are shown by numerical simulations. It is demonstrated that chaos occurs for a range of managerial policies, and the associated unpredictability is solely due to the dynamics of the interaction. We show that the straight line stabilization method is the appropriate management measure to control the chaos.
\end{abstract}

\section{Introduction}

Currently, research and development (R\&D) activities have become one of the core competitive points for manufactures. $R \& D$ input is also an important way to enhance technological strength, and R\&D activities can reduce cost and improve competitiveness. R\&D activity investment and technology spillover effects promote manufacturing development, and enterprise development conversely promotes investment in $\mathrm{R} \& \mathrm{D}$ activities.

R\&D has been one of the most important motivations for manufacturing development since the nineteen century. The choice of strategy and the decision rules for R\&D input are two key consideration factors. Dasgupta and Maskin [1] divided R\&D activities into two kinds which were competition and noncompetition based on the different structure of the income of innovation. We know that the R\&D activities can bring spillover effect; that is, one manufacturer can get the spillover effects of the R\&D activities from the other manufacturer. The influence of the technology spillover effect brought by the R\&D activities has been studied by many researchers. Aspremont and Jacquemin [2] firstly considered the spillover effect of technology and put forward Cournot competition in the product market. They proposed the twostage theory for $\mathrm{R} \& \mathrm{D}$ activities, which laid an important foundation for the later research. Gersbach and Schmutzler [3] considered a three-location duopoly model, including production and innovation locations choices, and examined the effects of the internal knowledge spillovers and external knowledge spillovers on the location of production and innovation. Bischi and Lamantia [4] studied R\&D competition duopoly games with spillover effects. Milstein and Tishler [5] used a two-stage model to describe the optimal R\&D choice of firms operation in an oligopoly market and predicted a U-shaped relationship between competition and innovation. Petit and Sanna-Randaccio [6] considered a two-country imperfect competition model and examined the influence of the firms mode of foreign expansion on the incentive innovation as well as the impact of $\mathrm{R} \& \mathrm{D}$ activities and technological spillovers on the international strategy. Luckraz [7] showed a note in a two-stage Cournot R\&D game model with isoelastic demand functions. Luckraz [8] demonstrated innovation (or Schumpeter's) cycles in a discrete and finite dynamic game of innovation and imitation and concluded that strategic interactions were sufficient to generate cycles. Grunfeld [9] presented a three-stage Cournot duopoly model, 
which under conditions identified by firms was chosen to service a foreign market through exports or localized production.

The references mentioned above assume that the manufacturers are completely rational, but the bounded rationality is, really, more in the realistic economic market because the manufacturers cannot always get the full information. Dynamic Cournot game models were discussed in the following references, in which players used output as the decision variable. Fanti et al. [10] analyzed the dynamics of a nonlinear Cournot duopoly with managerial delegation. Ma and Guo [11] studied the estimation accuracy by assuming that the second player makes his estimation based on recursive least-square (RLS) algorithm and compared the profit in two-period decision-making process with that in oneperiod decision-making process. Ma and Ji [12] considered a Cournot model in electric power triopoly with nonlinear inverse demand function and cost functions. Ma and $\mathrm{Tu}$ [13] studied the complexity of a duopoly game in the electricity market under the background of development of new energy with delayed bounded rationality. $\mathrm{Wu}$ and $\mathrm{Ma}$ [14] established and investigated the complexity of a multiproduct Cournot duopoly game with managerial delegation. Matsumoto and Nonaka [15] researched the complexity of a Cournot model with linear cost functions and complementary goods. Tramontana [16] and Tramontana and Elsadany [17] found two routes which were the flip bifurcations and the NeimarkSacker bifurcation to chaos in a duopoly and triopoly game model with isoelastic demand function and heterogeneous players, respectively. Yao et al. [18] analyzed a dynamic triopoly game model with isoelastic demand function and fully heterogeneous players: bounded rational, adaptive, and naive.

Nonlinear dynamic Bertrand game models were also researched in the following references, where players used price as the decision variable. Chen et al. [19] applied the Bertrand triopoly model with linear demand functions to study the competition in Chinese telecommunications market. Guo and $\mathrm{Ma}$ [20] studied the dynamics characteristics of nonlinear dynamic system in the closed-loop supply chain. $\mathrm{Ma}$ and Li [21] constructed dynamic Bertrand-Stackelberg pricing models in a risk-averse supply chain which followed these strategies: Bertrand game between the two manufacturers and Stackelberg game between the manufacturer and the retailer. Sun and $\mathrm{Ma}$ [22] introduce a triopoly Bertrand game model and applied it in Chinese cold rolled steel market.

Other models of nonlinear dynamical systems are as follows. $\mathrm{Ma}$ and $\mathrm{Pu}$ [23] researched the complex characteristics on a Cournot-Bertrand duopoly model with heterogeneous goods. Ma and Xie [24] compared and analyzed the complexity on dual-channel supply chain under different channel power structures and uncertain demand. Ma et al. [25] considered stability of a three-species symbiosis Lotka-Volterra model with discrete delays. Ma and Liu [26] investigated exact solutions for a generalized nonlinear Fokker-Planck diffusion equation with external force and absorption. Tu and Wang [27] studied the complexity and control of a dynamic masterslave Cournot triopoly game model.
However, studies of dynamic R\&D competition models with bounded manufacture were relatively rare. $\mathrm{Hu}$ et al. [28] investigated the complexity in a dynamic R\&D Cournot duopoly. Sheng et al. [29] discussed the local and global complexity of R\&D dynamic Cournot duopoly model. Li and $\mathrm{Ma}$ [30] analyzed the complex characteristics on three oligarchs R\&D competition models with heterogeneous players. The above three references all were Cournot competition models. This paper considers a dynamic R\&D two-stage input competition game model in the duopoly Bertrand oligopoly market, which more closely aligns with the actual economic market because the products generally have some differences in the real market.

The organization of this paper is as follows. In Section 2, we construct an R\&D two-stage input competition duopoly game model with bounded rational rules. We investigate the fixed points and local stability of the system, and complex system behaviors are shown by numerical simulations with changes to input adjustment speed and other parameters. In Section 3, we confirm that the chaotic systems sensitively are dependent on initial conditions, and Section 4 shows how the chaos can be controlled by the straight line stabilization method. Finally, Section 5 discusses and concludes the paper.

\section{The Model}

We consider two manufacturers producing alternative and heterogeneous products in the duopoly oligopoly market. $\mathrm{R} \& \mathrm{D}$ activities are divided into input and output decision stages. The first stage is an input competition, and we assume that the manufacturers follow bounded rational strategies. The second stage is the output decision, using price competition, and we assume the manufacturers seek maximum profit. The achievements of the R\&D activities are spread between the two manufacturers, which is called technology spillover in the competition process. At discrete times $t(t=$ $0,1,2, \ldots)$, manufacturer $X_{i}(i=1,2)$ supplies production $q_{i}(t)(i=1,2)$ for the market. Every manufacture should make an expectation for the rival's input in the next period to estimate the maximum corresponding profit for that period.

Following the classic Bertrand model, the demand functions for the two manufacture are

$$
\begin{aligned}
& q_{1}(t)=a_{1}-b_{1} p_{1}(t)+e_{1} p_{2}(t), \\
& q_{2}(t)=a_{2}-b_{2} p_{2}(t)+e_{2} p_{1}(t) .
\end{aligned}
$$

And the cost function for manufacturer $X_{i}(i=1,2)$ after their $\mathrm{R} \& \mathrm{D}$ activities is

$$
\begin{aligned}
C_{i}(t)=\left(A-x_{i}(t)-\beta_{i} x_{j}(t)\right) q_{i}(t), & \\
& (i, j=1,2, i \neq j),
\end{aligned}
$$

where $A$ is the positive variable cost parameter before the manufacturer undertakes the R\&D activities, and $\beta_{i}(i=1,2)$ is positive technology spillover between the two manufacturers. 
Combining (1) and (2), the profit for manufacturer $X_{i}(i=$ $1,2)$ at the price decision stage is

$$
\begin{gathered}
\pi_{i}(t)=p_{i}(t) q_{i}(t)-C_{i}(t)-\frac{\gamma_{i}}{2} x_{i}(t)^{2} \\
=\left(p_{i}(t)-A+x_{i}(t)+\beta_{i} x_{j}(t)\right) \\
\cdot\left(a_{i}-b_{i} p_{i}(t)+e_{i} p_{j}(t)\right)-\frac{\gamma_{i}}{2} x_{i}(t)^{2},
\end{gathered}
$$

$$
(i, j=1,2, i \neq j)
$$

where $\left(\gamma_{i} / 2\right) x_{i}(t)^{2}$ is the cost of R\&D investment.

Thus, the marginal profit of manufacturer $X_{i}(i=1,2)$ is

$$
\begin{aligned}
\frac{\partial \pi_{i}(t)}{\partial p_{i}(t)}= & \left(a_{i}-b_{i} p_{i}(t)+e_{i} p_{j}(t)\right) \\
& -b_{i}\left(p_{i}(t)-A+x_{i}(t)+\beta_{i} x_{j}(t)\right), \\
& (i, j=1,2, i \neq j) .
\end{aligned}
$$

From (4), we can get the manufacturer's reaction function to its competitor for a given period by backward induction, which is calculated for every possible production of the other manufacturer in a fixed time. For profit maximization, we can get the Nash-Bertrand equilibrium price as follows:

$$
\begin{array}{r}
p_{1}(t)=\frac{1}{4 b_{1} b_{2}-e_{1} e_{2}}\left[2 a_{1} b_{2}+e_{1} a_{2}+e_{1} b_{2} A+2 b_{1} b_{2} A\right. \\
\left.-\left(e_{1} b_{2} \beta_{2}+2 b_{1} b_{2}\right) x_{1}(t)+\left(e_{1} b_{2}+2 b_{1} b_{2} \beta_{1}\right) x_{2}(t)\right], \\
p_{2}(t)=\frac{1}{4 b_{1} b_{2}-e_{1} e_{2}}\left[2 a_{2} b_{1}+e_{2} a_{1}+b_{1} e_{2} A+2 b_{1} b_{2} A\right. \\
\left.+\left(b_{1} e_{2}+2 \beta_{2} b_{1} b_{2}\right) x_{1}(t)+\left(b_{1} e_{2} \beta_{1}+2 b_{1} b_{2}\right) x_{2}(t)\right] .
\end{array}
$$

For simplicity expression, we denote

$$
\begin{aligned}
f_{1}(t) & =p_{1}(t), \\
f_{2}(t) & =p_{2}(t), \\
k_{1} & =\frac{-\left(e_{1} b_{2} \beta_{2}+2 b_{1} b_{2}\right)}{4 b_{1} b_{2}-e_{1} e_{2}}, \\
k_{2} & =\frac{-\left(e_{1} b_{2}+2 b_{1} b_{2} \beta_{1}\right)}{4 b_{1} b_{2}-e_{1} e_{2}}, \\
k_{3} & =\frac{-\left(b_{1} e_{2}+2 b_{1} b_{2} \beta_{2}\right)}{4 b_{1} b_{2}-e_{1} e_{2}}, \\
k_{4} & =\frac{-\left(b_{1} e_{2} \beta_{1}+2 b_{1} b_{2}\right)}{4 b_{1} b_{2}-e_{1} e_{2}} .
\end{aligned}
$$

Thus, back to the first stage, from (3), (5), and (6), the $\mathrm{R} \& \mathrm{D}$ marginal profits of the input are

$$
\begin{aligned}
& \frac{\partial \pi_{1}(t)}{\partial x_{1}(t)} \\
& =\left(k_{1}+1\right)\left(a_{1}-b_{1} f_{1}(t)+e_{1} f_{2}(t)\right) \\
& +\left(-b_{1} k_{1}+e_{1} k_{3}\right)\left(f_{1}(t)-A+x_{1}(t)+\beta_{1} x_{2}(t)\right) \\
& -\gamma_{1} x_{1}(t) \\
& \frac{\partial \pi_{2}(t)}{\partial x_{2}(t)} \\
& =\left(k_{4}+1\right)\left(a_{2}-b_{2} f_{2}(t)+e_{2} f_{1}(t)\right) \\
& +\left(-b_{2} k_{4}+e_{2} k_{2}\right)\left(f_{2}(t)-A+x_{2}(t)+\beta_{2} x_{1}(t)\right) \\
& -\gamma_{2} x_{2}(t) \text {. }
\end{aligned}
$$

Suppose that the R\&D input decision of manufacturer $X_{i}(i=1,2)$ is bounded rational suppliers, and the manufacturer makes the next-period R\&D input decision based on their current input and the marginal profit of the R\&D input. The dynamic adjustment mechanism can be written as

$$
x_{i}(t+1)=x_{i}(t)+\alpha_{i} x_{i}(t) \frac{\partial \pi_{i}(t)}{\partial x_{i}(t)} \quad(i=1,2),
$$

where $\alpha_{i}(i=1,2)$ is the speed adjustment parameter of the $\mathrm{R} \& \mathrm{D}$ input, and $\partial \pi_{i}(t) / \partial x_{i}(t)(i=1,2)$ is the marginal profit of the R\&D input.

Combining (7) and (8), a new dynamic R\&D input competition game model with bounded rational strategy can be described by a 2-dimensional dynamic system:

$$
\begin{aligned}
& x_{1}(t+1)=x_{1}(t)+\alpha_{1} x_{1}(t) \\
& \cdot\left[\left(k_{1}+1\right)\left(a_{1}-b_{1} f_{1}(t)+e_{1} f_{2}(t)\right)\right. \\
& +\left(-b_{1} k_{1}+e_{1} k_{3}\right)\left(f_{1}(t)-A+x_{1}(t)+\beta_{1} x_{2}(t)\right) \\
& \left.\quad-\gamma_{1} x_{1}(t)\right], \\
& x_{2}(t+1)=x_{2}(t)+\alpha_{2} x_{2}(t) \\
& \cdot\left[\left(k_{4}+1\right)\left(a_{2}-b_{2} f_{2}(t)+e_{2} f_{1}(t)\right)\right. \\
& \quad+\left(-b_{2} k_{4}+e_{2} k_{2}\right)\left(f_{2}(t)-A+x_{2}(t)+\beta_{2} x_{1}(t)\right) \\
& \left.\quad-\gamma_{2} x_{2}(t)\right] .
\end{aligned}
$$

2.1. Fixed Points and Local Stability Analysis. In system (9), $\alpha_{i}(i=1,2)$ is taken as the bifurcation parameter, and the other parameters are constant. Let $a_{1}=9, a_{2}=7, b_{1}=$ $1.4, b_{2}=1.2, e_{1}=0.3, e_{2}=0.5, A=5, \gamma_{1}=1.6, \gamma_{2}=$ $1.8, \beta_{1}=0.2, \beta_{2}=0.3$.

Let $x_{i}(t+1)=x_{i}(t)$; then we have three meaningful fixed points: $E_{1}=(0,1.5451), E_{2}=(1.9486,0), E_{3}=\left(x_{1}^{*}, x_{2}^{*}\right)=$ $(5.5558,4.4831) . E_{1}$ and $E_{2}$ are boundary equilibrium points that mean that at least one player is out of the market. Therefore, we only consider the stability of the Nash equilibrium point $E_{3}$. 
To investigate the local stability of Nash equilibrium point $E_{3}$, we first obtain the Jacobian matrix of system (9) at $E_{3}$. For simplicity, we denote

$$
J=\left(\begin{array}{ll}
j_{11} & j_{12} \\
j_{21} & j_{22}
\end{array}\right),
$$

where

$$
\begin{aligned}
j_{11} & =1+\alpha_{1} x_{1}^{*}\left[2\left(k_{1}+1\right)\left(-b_{1} k_{1}+e_{1} k_{3}\right)-\gamma_{1}\right]=1 \\
& -1.9933 \alpha_{1}, \\
j_{12} & =\alpha_{1} x_{1}^{*}\left[\left(k_{1}+1\right)\left(-b_{1} k_{2}+e_{1} k_{4}\right)\right. \\
& \left.+\left(k_{2}+\beta_{1}\right)\left(-b_{1} k_{1}+e_{1} k_{3}\right)\right]=0.1159 \alpha_{1}, \\
j_{21} & =\alpha_{2} x_{2}^{*}\left[\left(k_{4}+1\right)\left(-b_{2} k_{3}+e_{2} k_{1}\right)\right. \\
& \left.+\left(k_{3}+\beta_{2}\right)\left(-b_{2} k_{4}+e_{2} k_{2}\right)\right]=0.0726 \alpha_{2}, \\
j_{22} & =1+\alpha_{2} x_{2}^{*}\left[2\left(k_{4}+1\right)\left(-b_{2} k_{4}+e_{2} k_{2}\right)-\gamma_{2}\right]=1 \\
& -2.0632 \alpha_{2} .
\end{aligned}
$$

Then, the characteristic equation of system (9) at $E_{3}$ is

$$
f(\lambda)=\lambda^{2}-\left(j_{11}+j_{22}\right) \lambda+\left(j_{11} j_{22}-j_{12} j_{21}\right) .
$$

According to the Jury test, the local stable conditions for Nash equilibrium $E_{3}$ are

(i) $1-\left(j_{11}+j_{22}\right)+\left(j_{11} j_{22}-j_{12} j_{21}\right)=4.1042 \alpha_{1} \alpha_{2}>0$,

(ii) $1+\left(j_{11}+j_{22}\right)+\left(j_{11} j_{22}-j_{12} j_{21}\right)=4-3.9865 \alpha_{1}-$ $4.1264 \alpha_{2}+4.1042 \alpha_{1} \alpha_{2}>0$

(iii) $j_{11} j_{22}-j_{12} j_{21}=-1.9933 \alpha_{1}-2.0632 \alpha_{2}+4.1042 \alpha_{1} \alpha_{2}<$ 0 .

Solving the above equations, the local stable region of the Nash equilibrium point with positive $\left(\alpha_{1}, \alpha_{2}\right)$ is shown in Figure 1. System (9) is asymptotically stable when the R\&D input speed adjustment parameters are in the stable region. For parameters in the stable region, all R\&D inputs will be stable at Nash equilibrium point $E_{3}$ after a limited number of games for any given initial datum as shown in Figure 2.

2.2. Dynamics Characteristics of System (5). To understand the dynamic evolution of the system, we show the dynamic features of system (9) with increasing $\alpha_{i}(i=1,2)$ by numerical simulations, such as bifurcation diagrams, largest Lyapunov exponents, strange attractors, and time diagram.

Complex characteristics of nonlinear dynamic systems are generally investigated by varying one parameter while the others are fixed. The occurrence of chaos by period doubling bifurcations as one parameter is increased, which is called a codimension-one route to chaos.

First, we discuss manufacturer $X_{1}$ accelerating $\alpha_{1}$. The Nash equilibrium point will become unstable if $\alpha_{1}$ is out of the stable region.

Figure 3 shows the bifurcation diagram and corresponding largest Lyapunov exponents with respect to $\alpha_{1}\left(\alpha_{1} \in\right.$
$(0,1.5061])$ for $\alpha_{2}=0.36$. The bifurcation diagram is an illustrative way for dynamic systems analysis and describes how the dynamic behavior of the dynamic systems alters as one parameter is changed. Bifurcations involve qualitative changes of behavior of the system, such as from equilibrium to periodic cycles or chaos. The evolution of system (9) is successively stable state, period doubling bifurcation, chaos, and intermittent chaos, including both high cycle bifurcations and chaos. The potential meanings of the bifurcation point is the critical point for the system from one state to another. Calculation of the largest Lyapunov exponents is another way to quantitatively analyze dynamic system characteristics. The largest Lyapunov exponents are negative when dynamic systems are at the stable state and high order cycles and positive while the system is in a chaotic state. The Lyapunov exponents can also differentiate between high order cycles and aperiodic behavior, and larger positive exponent means stronger chaos. It is easier to understand the dynamic properties by comparing with the bifurcation diagram.

The R\&D input evolution of the duopoly manufacturers starts with equilibrium state, undergoes period doubling, and ends with a chaotic state with increased $\alpha_{1}$. System (9) is stable at the Nash equilibrium point for $0<\alpha_{1}<0.9990$. Phase diagrams for 2, 4, and 8 cycle orbits are shown in Figure 4 . The strange attractor indicates inherent regularity of the chaos, which is an important characteristic of chaos. Figure 5 shows three classic chaos attractors for system (9). Figure 6(a) shows the phase diagram of system (9) for $\left(\alpha_{1}=\right.$ 1.39, $\alpha_{2}=0.36$ ) when system (9) in a chaotic state. The motion of the chaos is an aperiodic series. The phase diagrams for 3 and 6 cycle orbits are shown in Figures 6(b) and 6(c), respectively.

Similarly, Figure 7 shows the bifurcation diagram and corresponding largest Lyapunov exponents with respect to $\alpha_{2}\left(\alpha_{2} \in(0,1.7816]\right)$ when $\alpha_{1}=0.42$. System (9) is stable at the Nash equilibrium point for $0<\alpha_{2}<0.9624$. When $\alpha_{2}>0.9624$, system (9) loses stability and undergoes period doubling bifurcations to chaos. Figure 8 shows three typical chaos attractors of system (9).

The parameter basin plot is a more powerful tool than $1 \mathrm{D}$ bifurcation diagram in the numerical analysis, which is also called 2D bifurcation diagrams and assigns different colors in a 2D parameter space to stable cycles of different periods.

Figure 9 shows parameter basin for periodic cycles with the change of manufacturers' adjustment speeds $\alpha_{1}$ and $\alpha_{2}$ and assigns different colors to stable states (green), 2periodic cycle (blue), 3-periodic cycle (red), 4-periodic cycle (cyan), 6-periodic cycle (black), 8-periodic cycle (yellow), nonconvergent chaos (orange), and divergence (white). From Figure 9, we can more clearly see that system (9) goes into chaos by two doubling period bifurcation routes with the increase of manufacturers' adjustment speed $\alpha_{i}(i=1,2)$. System (9) firstly goes through 2-periodic cycle, 4-periodic cycle, and 8-periodic cycle to chaos. Then, system (9) goes through 3-periodic cycle to chaos or 3-periodic cycle and 6periodic cycle to chaos.

Figure 10 shows the bifurcation diagram with the change of the demand elasticity coefficient $b_{i}(i=1,2)$. System (9) 


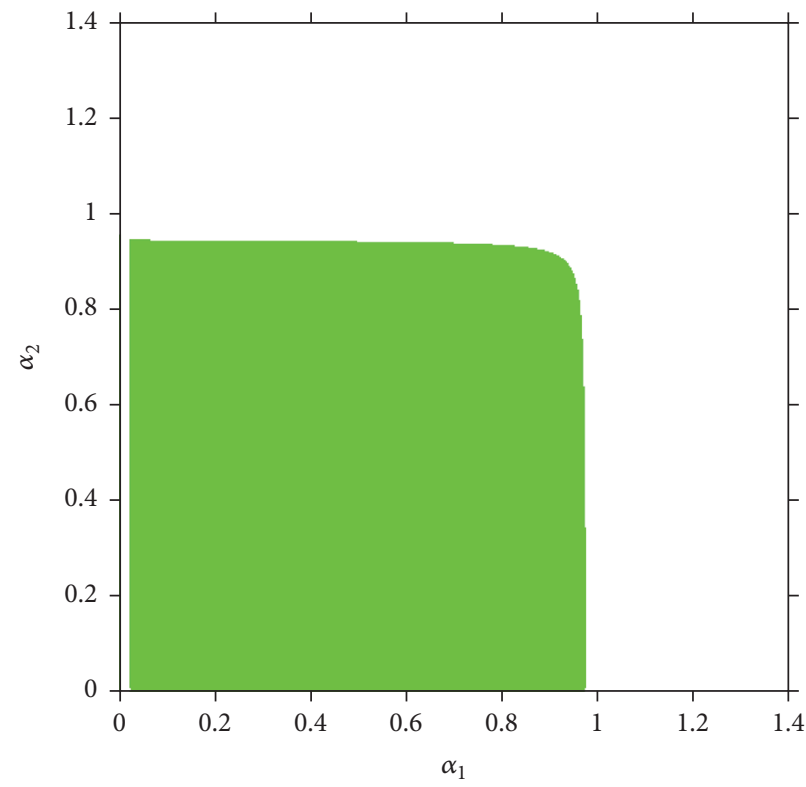

FIGURE 1: Stable region of system (9) with $\left(\alpha_{1}, \alpha_{2}\right)$.

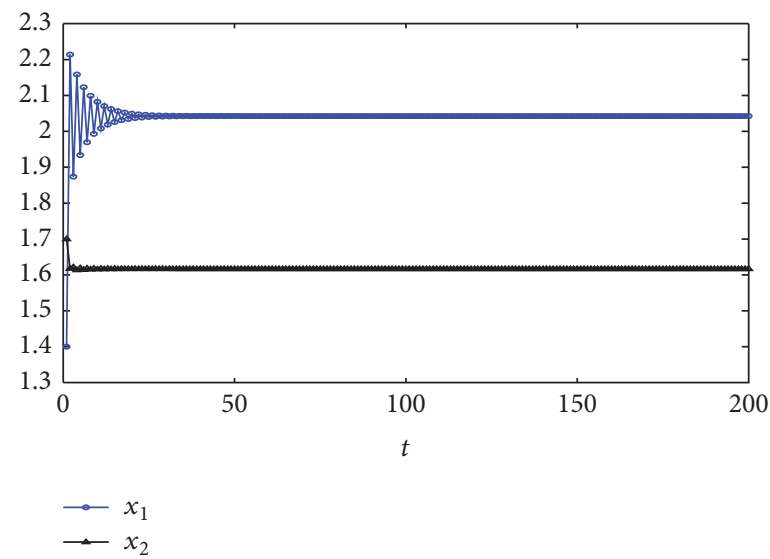

Figure 2: Time diagram of the input for $\left(\alpha_{1}=0.92, \alpha_{2}=0.36\right)$.

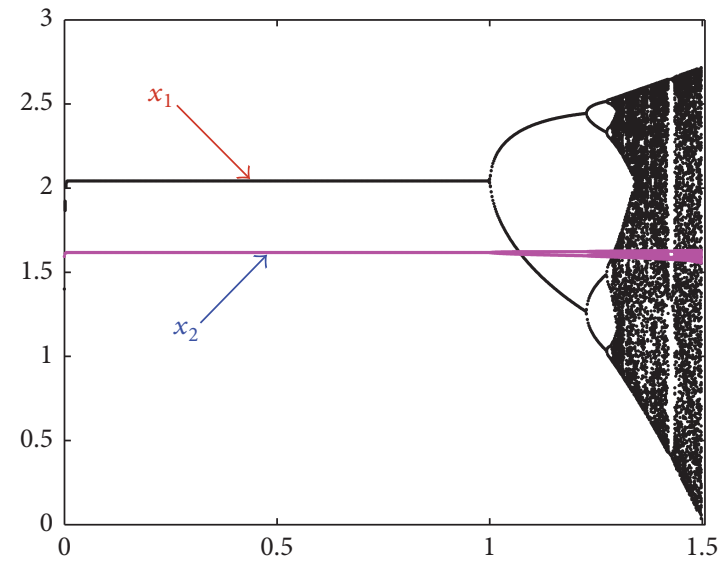

$\alpha_{1}$

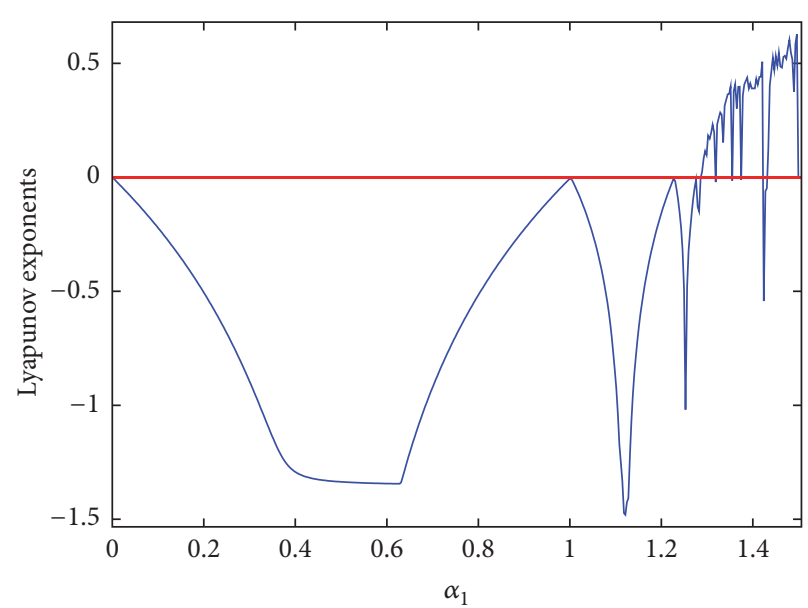

FIGURE 3: Bifurcation diagram and corresponding largest Lyapunov exponent with $\alpha_{1} \in(0,0.302]$, for $\left(\alpha_{2}=0.039, \alpha_{3}=0.037\right)$. 


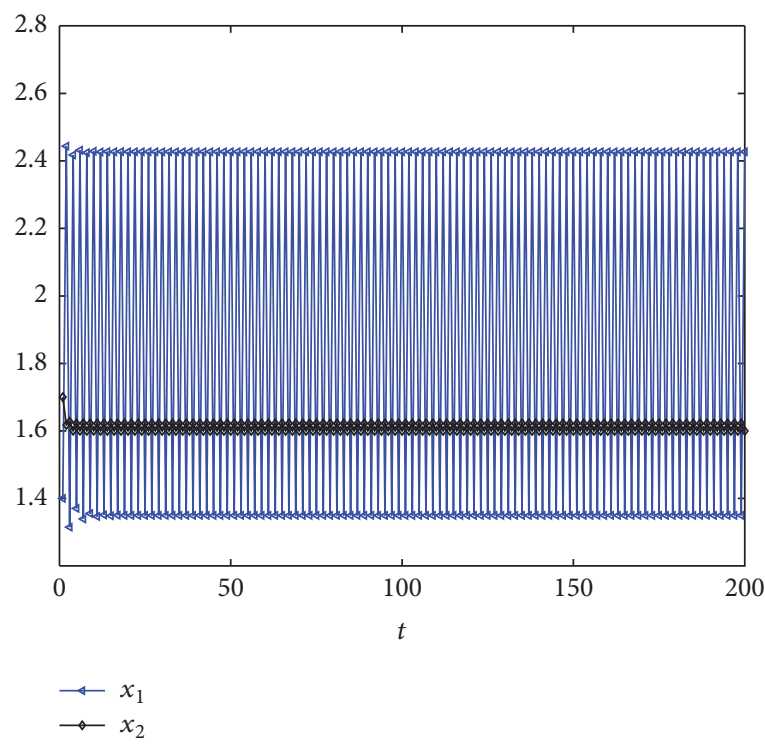

(a)

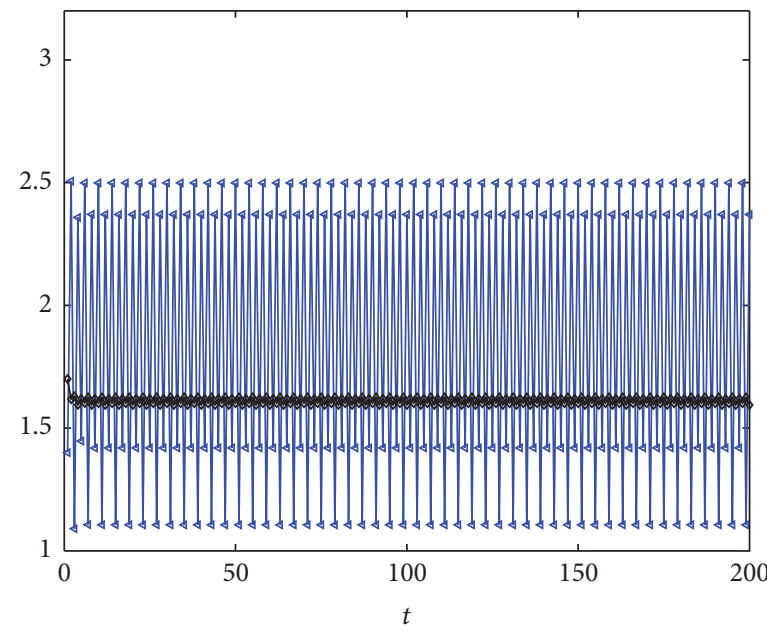

$\leftarrow x_{1}$

(b)

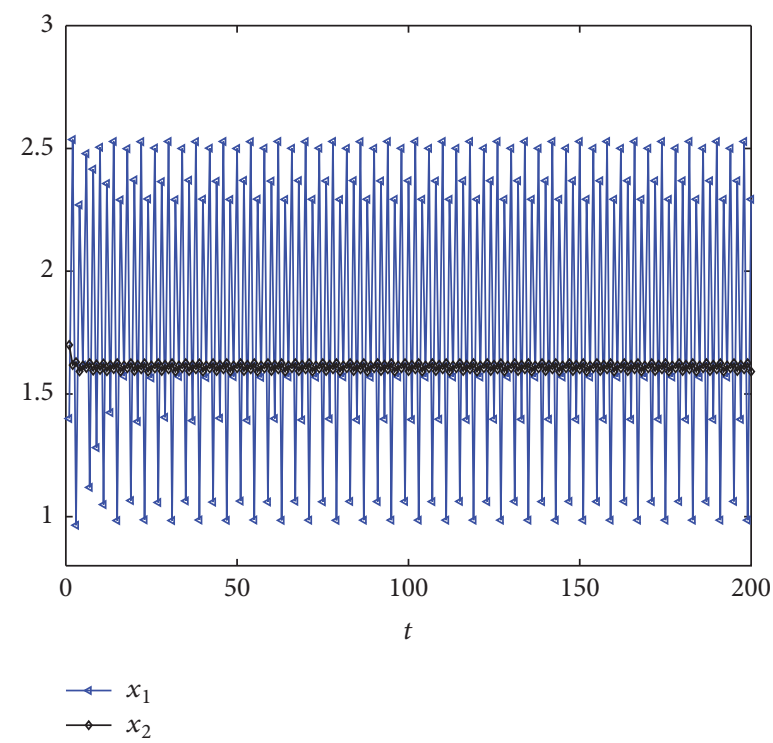

(c)

Figure 4: Phase diagram of system (9) for (a) $\left(\alpha_{1}=1.18, \alpha_{2}=0.36\right)$; (b) $\left(\alpha_{1}=1.25, \alpha_{2}=0.36\right)$; (c) $\left(\alpha_{1}=1.285, \alpha_{2}=0.36\right)$.

is divergent or in a chaotic state if $b_{i}(i=1,2)$ is too small, and the Nash equilibrium is changed with increasing of $b_{i}(i=1,2)$. Manufacturer $X_{i}(i=1,2)$ input first increases and then decreases, but the input of the other manufacturer monotonically decreases.

Figure 11 shows the bifurcation diagram with the change of the demand elasticity coefficient $e_{i}(i=1,2)$. System (9) is divergence or in a chaotic state if $e_{i}(i=1,2)$ is too large, and the Nash equilibrium is changed with increasing of $e_{i}(i=$ 1,2). Manufacturer $X_{i}(i=1,2)$ input first increases and then decreases.

Figure 12 shows the bifurcation diagram with the change of the variable cost parameter $A$. System (9) is in a periodic cycle or a chaotic state if $A$ is too small or too large, respectively. The system has no economic meaning if $A$ is too large. Within the domain of economic meaning, the Nash equilibrium of system (9) is decreasing with increasing of $A$.

\section{The Sensitive Dependence on Initial Conditions}

Sensitivity to initial conditions is one of the most important characteristics of chaos. Thus, even a small difference between initial R\&D inputs may lead to significant loss while the 


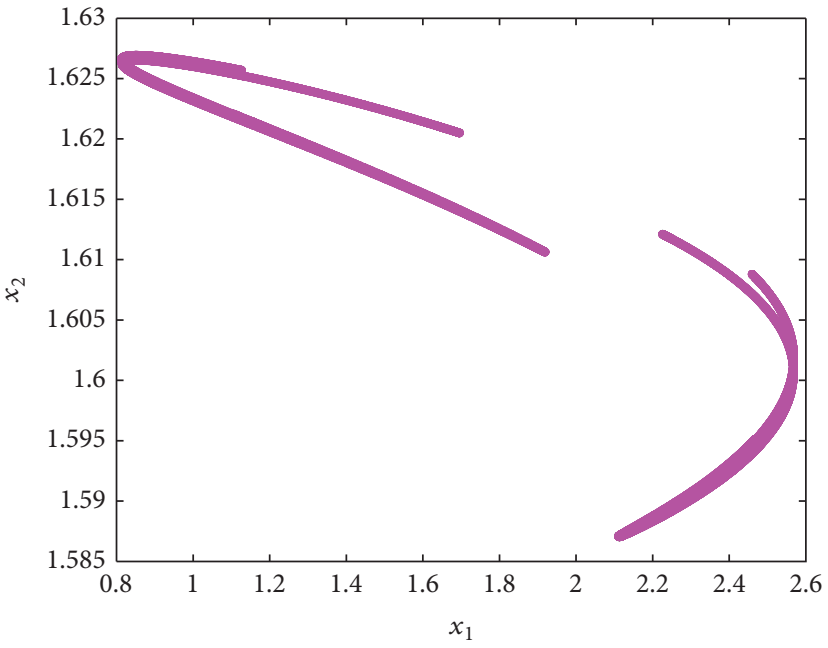

(a)

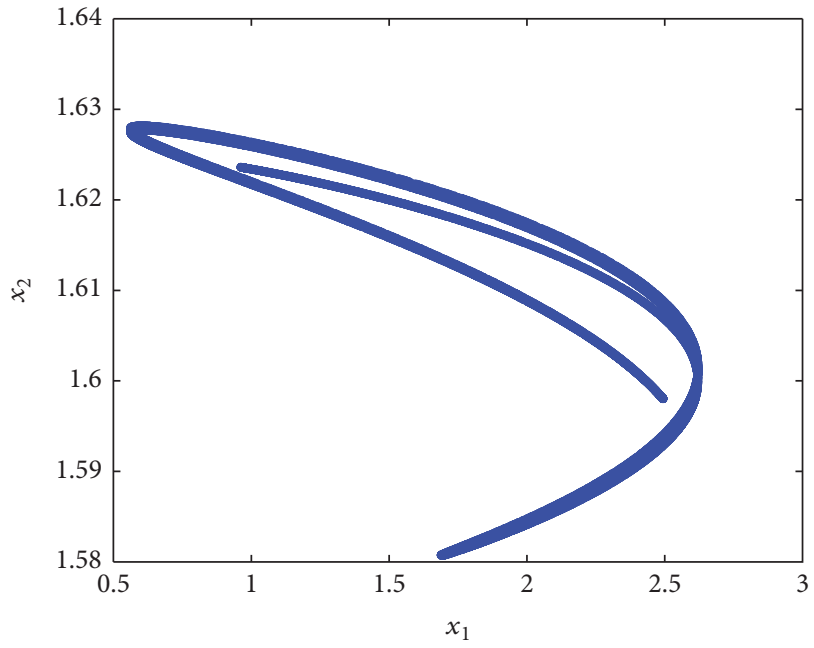

(b)

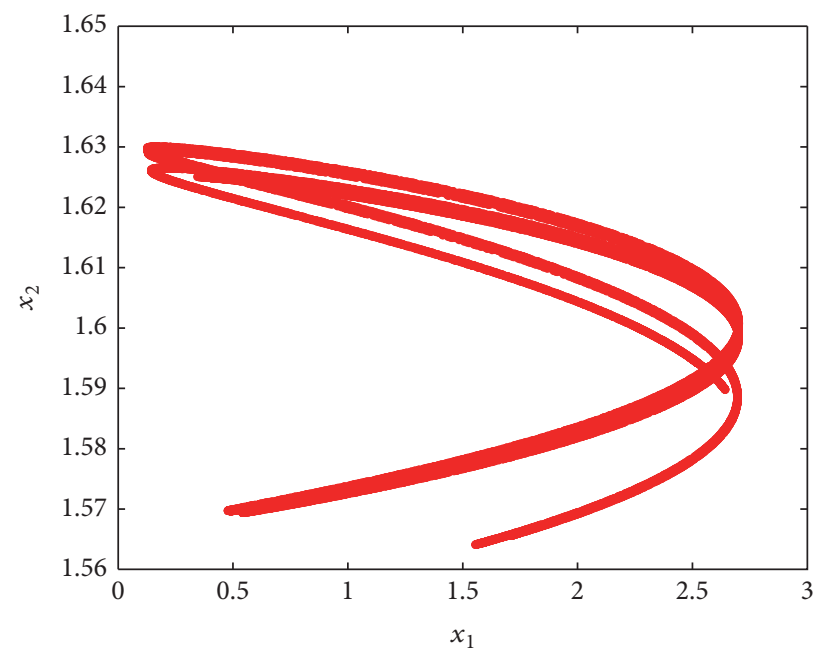

(c)

FIGURE 5: Chaos attractors of system (9) for (a) $\left(\alpha_{1}=1.33, \alpha_{2}=0.36\right)$; (b) $\left(\alpha_{1}=1.39, \alpha_{2}=0.36\right)$; (c) $\left(\alpha_{1}=1.48, \alpha_{2}=0.36\right)$.

system is in a chaotic state. Figures 13 and 14 show the relationships between inputs and time, which confirm that system (9) has significant sensitivity to initial conditions. Figures 13(a) and 14(a) show two different evolution tracks of $x_{1}$ and $x_{2}$ with different initial data, respectively. Figures 13(b) and 14(b) show the variance of $x_{1}$ and $x_{2}$ with different initial data by time, respectively. They are very similar at first, but the difference between them becomes rabid and unpredictable after several game times. Thus, just a slight difference between initial data may cause significantly different game results.

\section{Chaos Control}

Chaos can break regular economic systems, causing a confused and unpredictable market; that is, the system may fluctuate and become random-like and seemingly unpredictable.
To eliminate the negative effect of chaos, the straight line stabilization method is applied.

Recently, $\mathrm{Xu}$ et al. [31] and Yang et al. [32] introduced a straight line stabilization control method. We utilize this method to control the chaos of system (9). The external control signal is as follows:

$$
\varepsilon=\left(\begin{array}{l}
\varepsilon_{1} \\
\varepsilon_{2}
\end{array}\right)=(\mu I-J)\left(\begin{array}{l}
x_{1}(t)-x_{1}^{*} \\
x_{2}(t)-x_{2}^{*}
\end{array}\right),
$$

where $|\mu|<1$ is the feedback control parameter and other parameters are the same as in Section 2.

Substituting the external control signal (13) into system (5), the controlled system becomes

$$
\begin{aligned}
& x_{1}(t+1)=x_{1}(t)+\alpha_{1} x_{1}(t) \\
& \cdot\left[\left(k_{1}+1\right)\left(a_{1}-b_{1} f_{1}(t)+e_{1} f_{2}(t)\right)\right.
\end{aligned}
$$




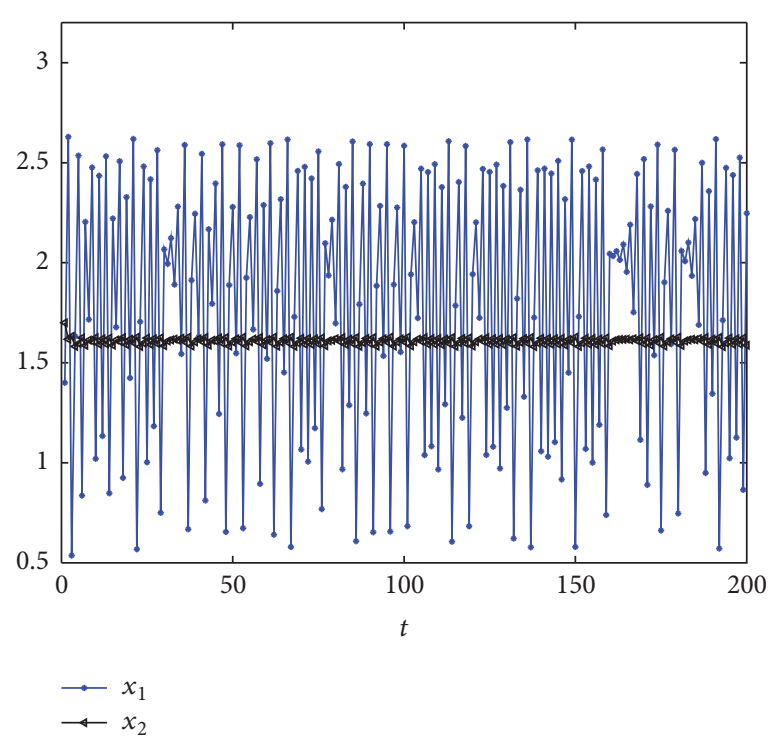

(a)

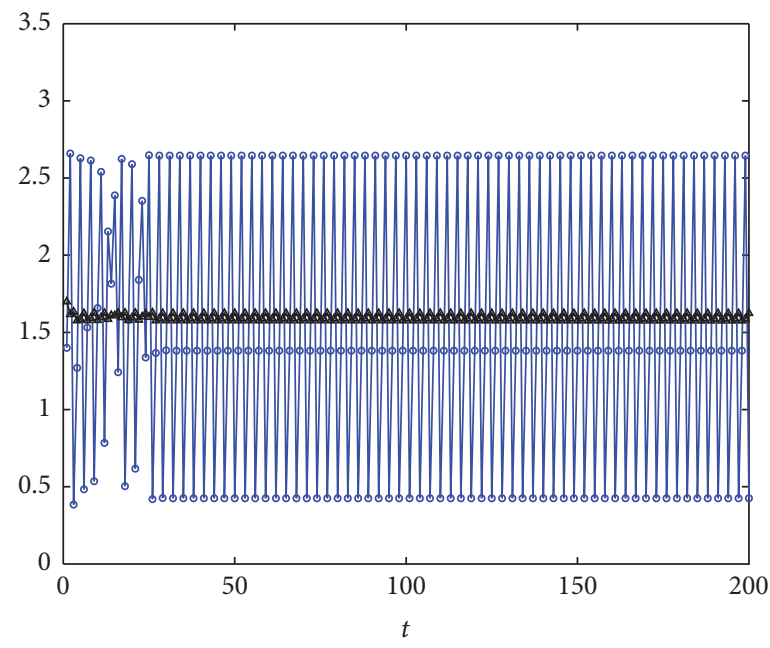

$\begin{array}{ll}\longrightarrow & x_{1} \\ \rightarrow & x_{2}\end{array}$

(b)

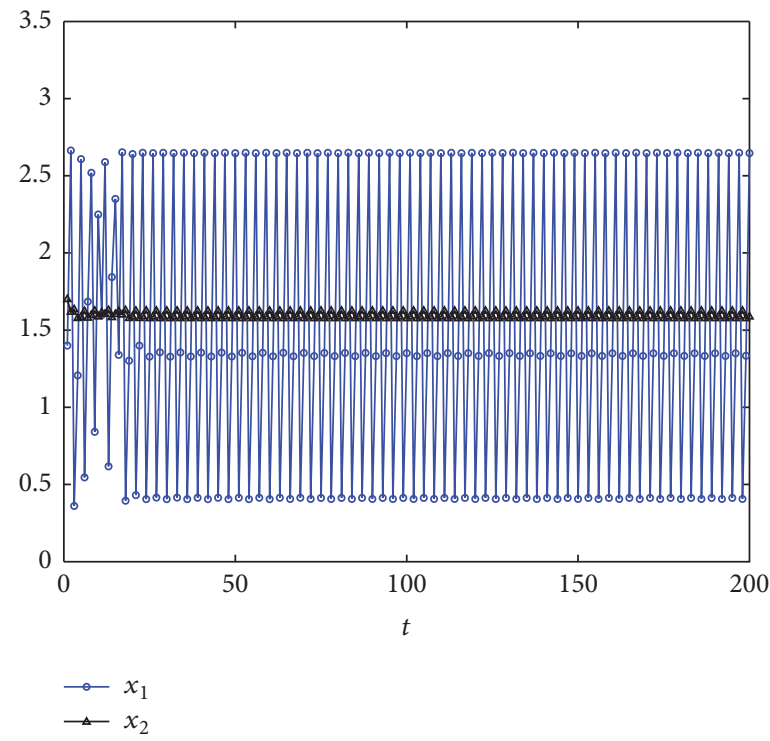

(c)

Figure 6: Phase diagram of system (9) for (a) $\left(\alpha_{1}=1.39, \alpha_{2}=0.36\right)$; (b) $\left(\alpha_{1}=1.423, \alpha_{2}=0.36\right)$; (c) $\left(\alpha_{1}=1.428, \alpha_{2}=0.36\right)$.

$$
\begin{aligned}
& +\left(-b_{1} k_{1}+e_{1} k_{3}\right)\left(f_{1}(t)-A+x_{1}(t)+\beta_{1} x_{2}(t)\right) \\
& \left.-\gamma_{1} x_{1}(t)\right]+\varepsilon_{1}, \\
& x_{2}(t+1)=x_{2}(t)+\alpha_{2} x_{2}(t) \\
& \cdot\left[\left(k_{4}+1\right)\left(a_{2}-b_{2} f_{2}(t)+e_{2} f_{1}(t)\right)\right. \\
& +\left(-b_{2} k_{4}+e_{2} k_{2}\right)\left(f_{2}(t)-A+x_{2}(t)+\beta_{2} x_{1}(t)\right) \\
& \left.-\gamma_{2} x_{2}(t)\right]+\varepsilon_{2} .
\end{aligned}
$$

For $\left(\alpha_{1}=1.39, \alpha_{2}=0.36\right)$, the bifurcation diagram in Figure 15 shows that controlled system (14) restabilizes at the
Nash equilibrium point for $-1<\mu<0.1362$. This indicates that chaos control of system (9) can be realized by adding a very small perturbation. Other complex dynamic behaviors of the system can also be controlled by similar straight line stabilization.

\section{Conclusions}

This paper shows competitive interactions of a two-stage $\mathrm{R} \& \mathrm{D}$ input competition duopoly game model with bounded rational strategy and asymmetric spillovers by a nonlinear dynamic game model and numerical simulations. Under certain conditions, oscillatory and chaos behaviors can occur. 


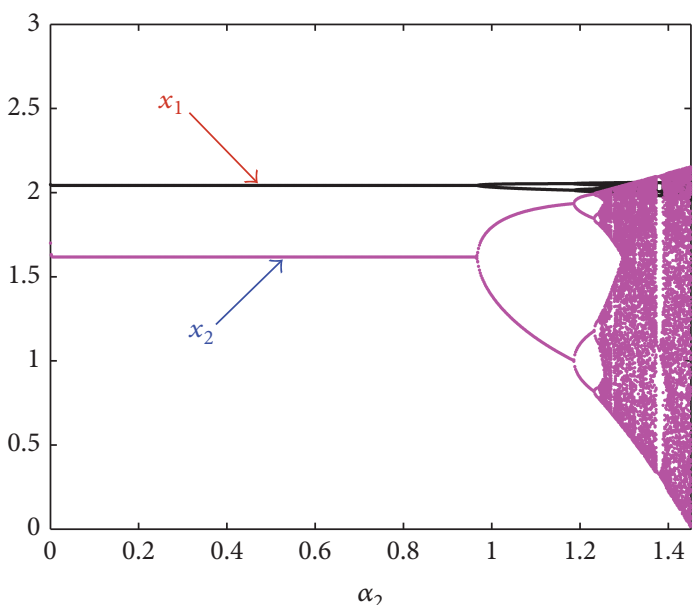

(a)

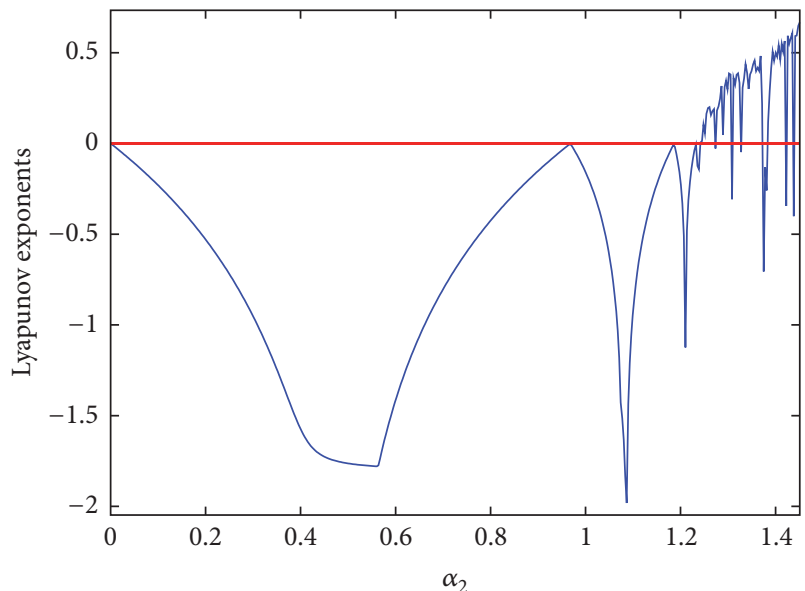

(b)

FIgURE 7: Bifurcation diagram (a) and corresponding largest Lyapunov exponents (b), with $\alpha_{2} \in(0,1.4510]$ for $\alpha_{1}=0.42$.

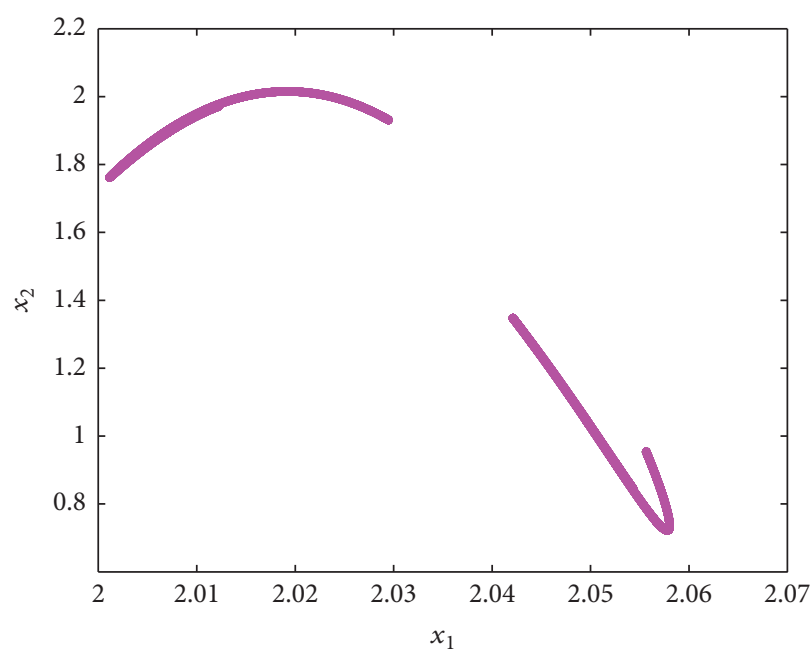

(a)

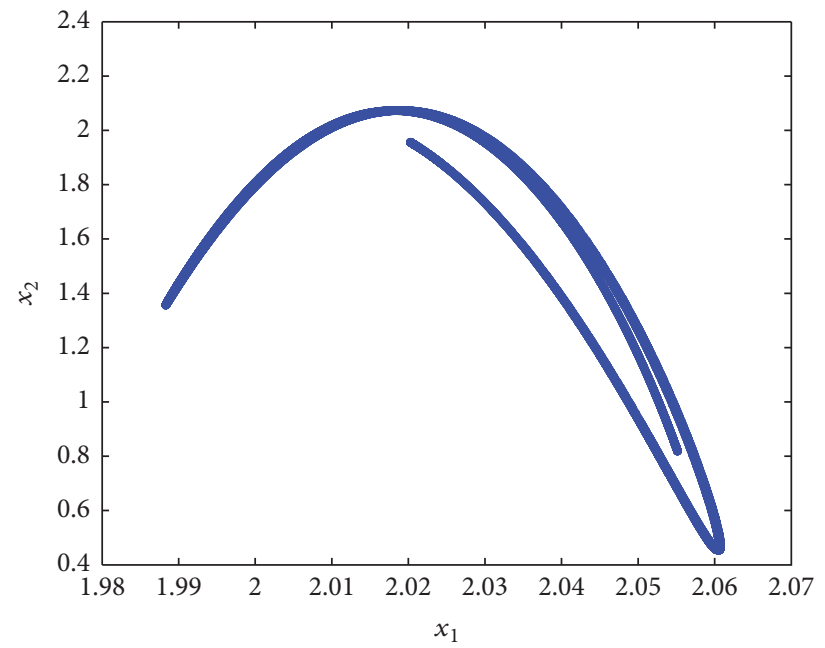

(b)

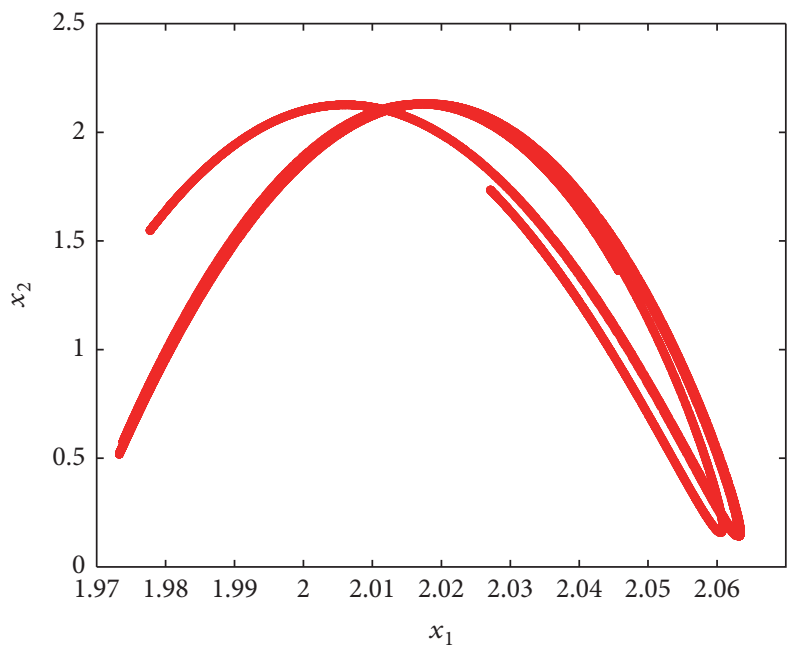

(c)

FiguRE 8: Chaos attractors for (a) $\left(\alpha_{1}=0.42, \alpha_{2}=1.26\right)$; (b) $\left(\alpha_{1}=0.42, \alpha_{2}=1.34\right)$; (c) $\left(\alpha_{1}=0.42, \alpha_{2}=1.42\right)$. 


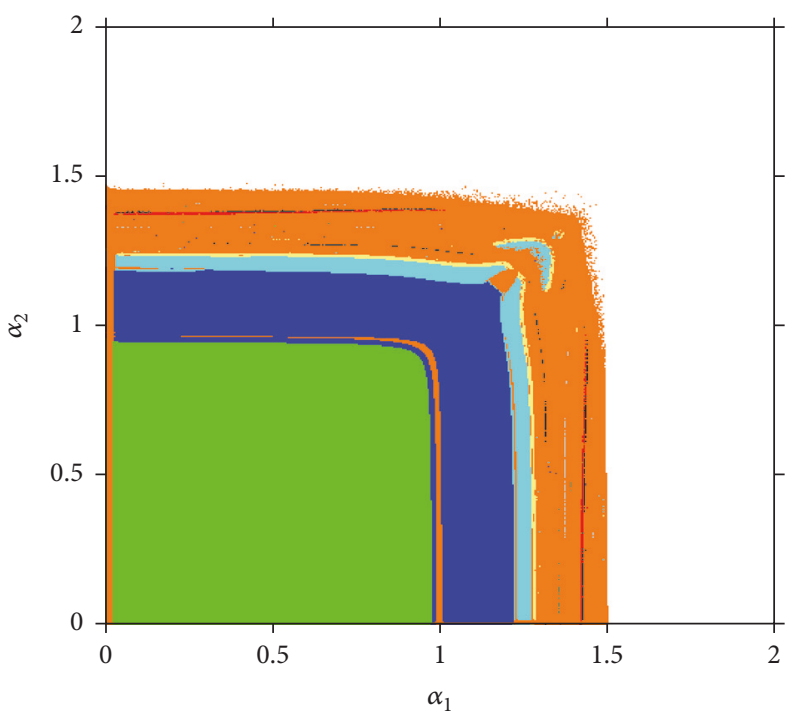

FIGURE 9: Parameter basins for periodic cycles with the change of $\alpha_{1}$ and $\alpha_{2}$.

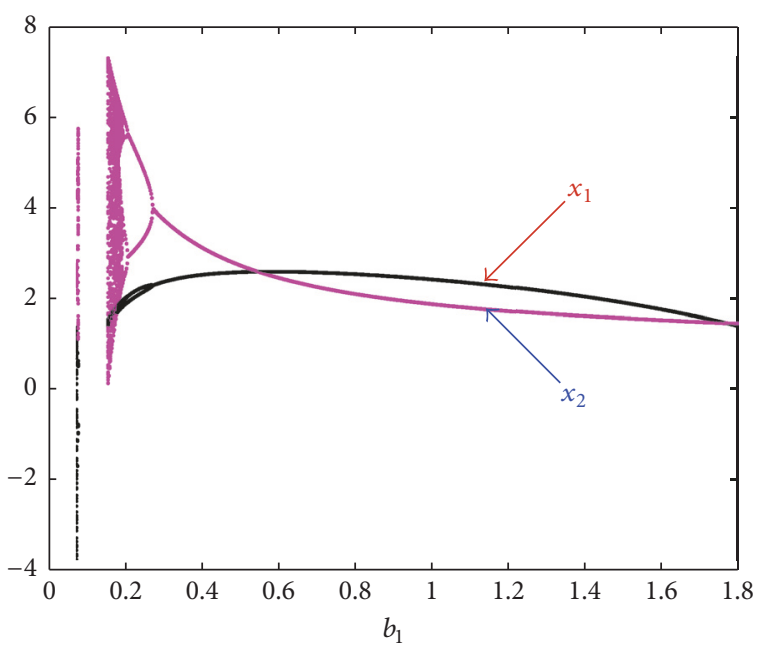

(a)

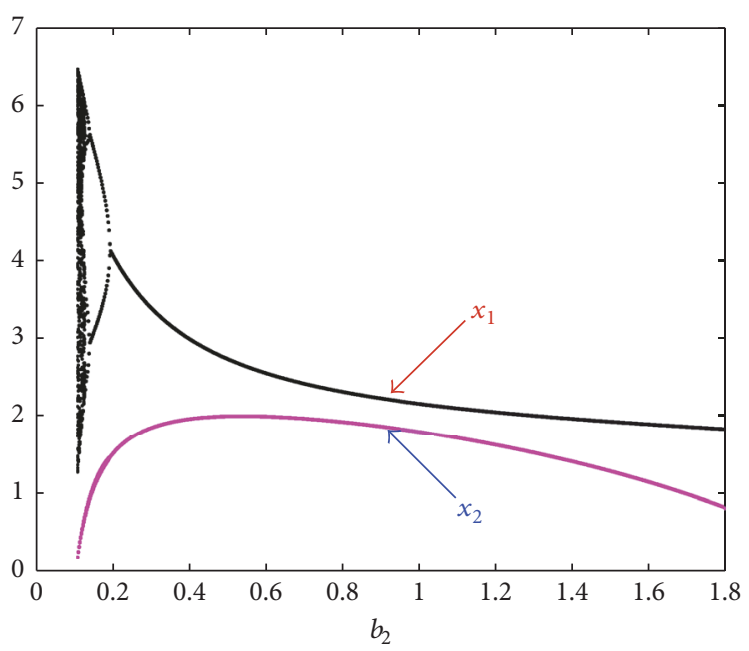

(b)

FIgURE 10: Bifurcation diagram for (a) $b_{1} \in(0,1.8]$; (b) $b_{2} \in(0,1.8]$ and $\left(\alpha_{1}=0.42, \alpha_{2}=0.36\right)$.

While the model describes the system for cost reduction, this structure can be generally applied to other microeconomic relationships shape competitive decisions for manufacturing.

Nash equilibrium region and local stable conditions are derived. The effects of input adjustment speed, demand elasticity, product substitution elasticity, variable cost, and technology spillover level on system dynamic features are shown by numerical simulations, that is, bifurcation diagrams, largest Lyapunov exponents, strange attractors, phase diagrams, and sensitive analysis on initial conditions. When the input adjust speed is too large, demand elasticity, variable cost, and too small product substitution elasticity may cause the system to become chaotic following the period doubling bifurcation route. Manufacturers can raise demand elasticity, decrease product substitution, reduce variable cost, and increase technology spillovers of their rivals to enhance competitiveness. The derived results provide some theoretical implications for manufacturers about $R \& D$ activities input and output decisions in real economic markets.

Chaos causes significant problems for manufacturers to forecast the market and formulate decision plans. Chaotic systems can be returned to the Nash equilibrium point and complex system behaviors can be eliminated by the straight line stabilization method. 


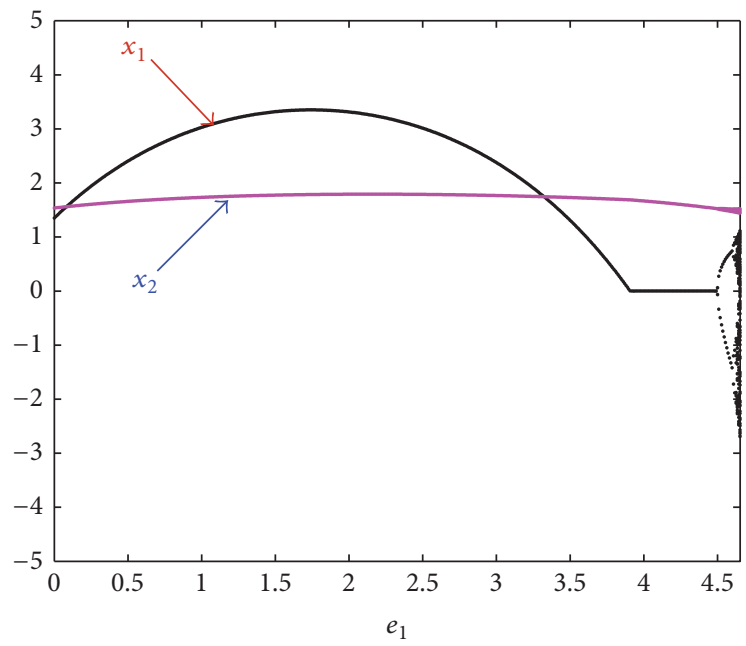

(a)

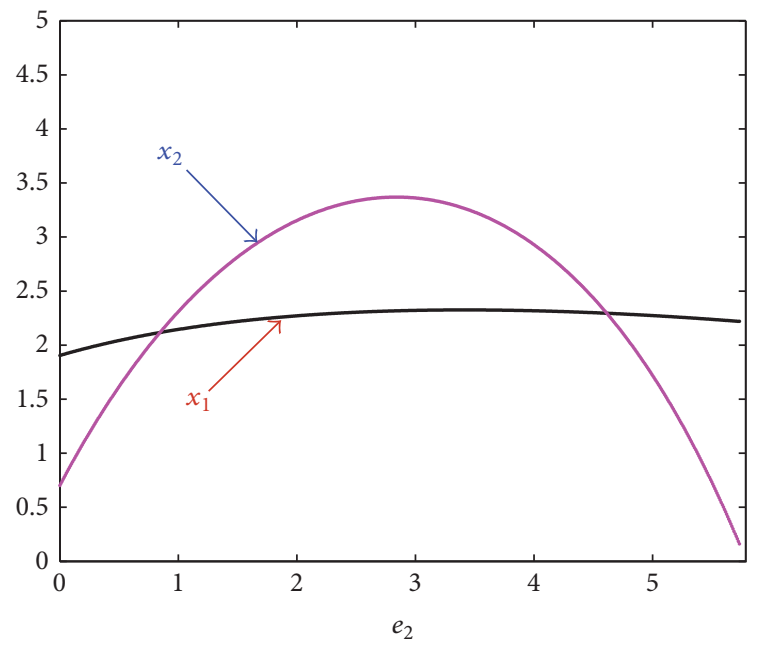

(b)

Figure 11: Bifurcation diagram for (a) $e_{1} \in(0,4.6531]$; (b) $e_{2} \in(0,5.7857]$ and $\left(\alpha_{1}=0.42, \alpha_{2}=0.36\right)$.

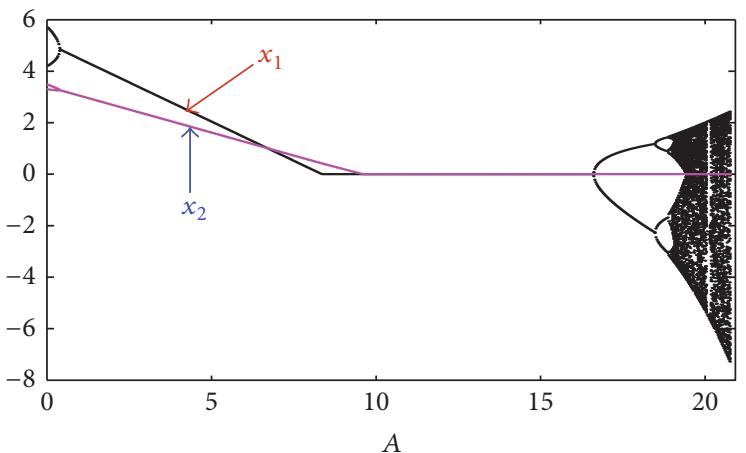

FIgURE 12: Bifurcation diagram for $A \in(0,0,20.9184]$ and $\left(\alpha_{1}=0.42, \alpha_{2}=0.36\right)$.

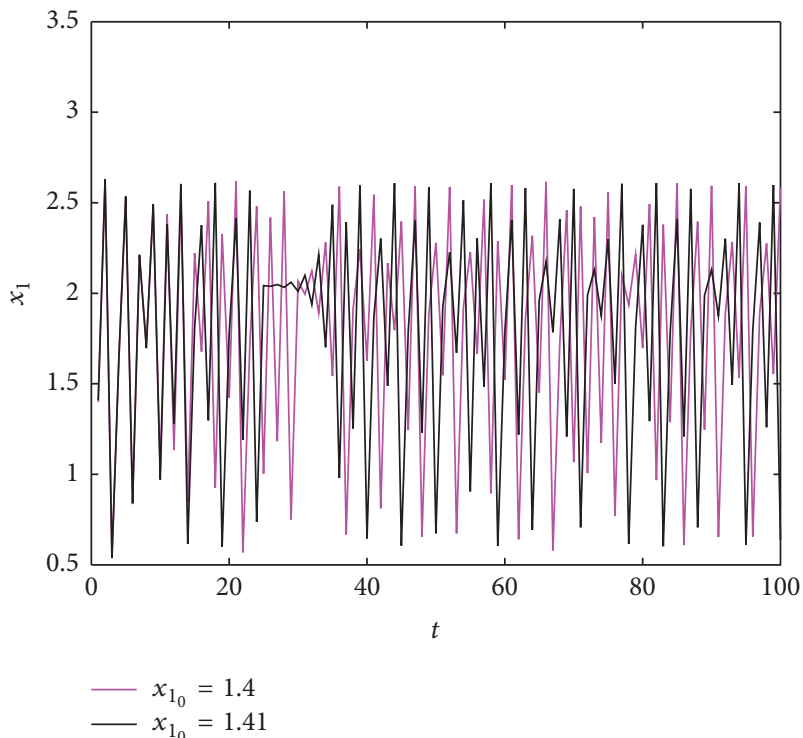

(a)

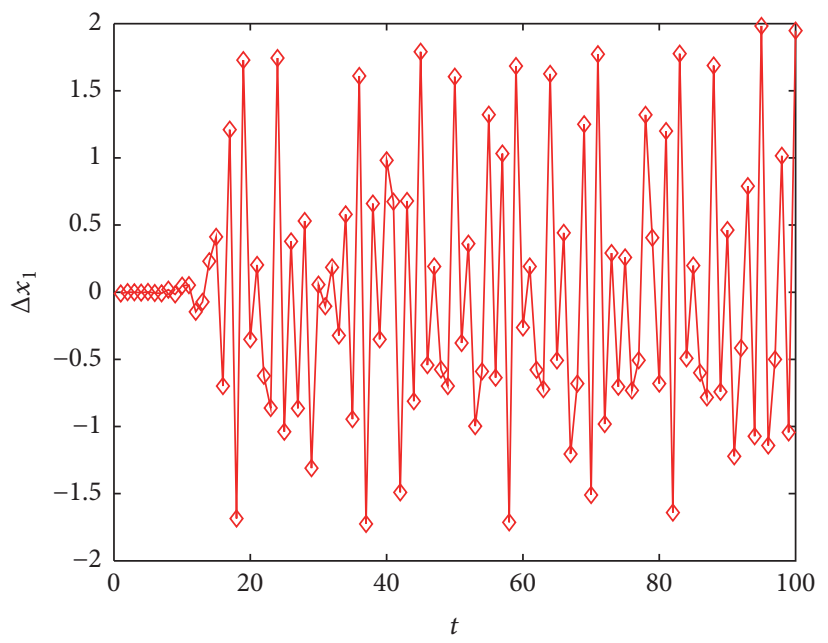

(b)

Figure 13: The two orbits and difference of $x_{1}$-coordinates for initial points $(1.4,1.7)$ and $(1.41,1.7)$ and $\left(\alpha_{1}=1.39, \alpha_{2}=0.36\right)$. 


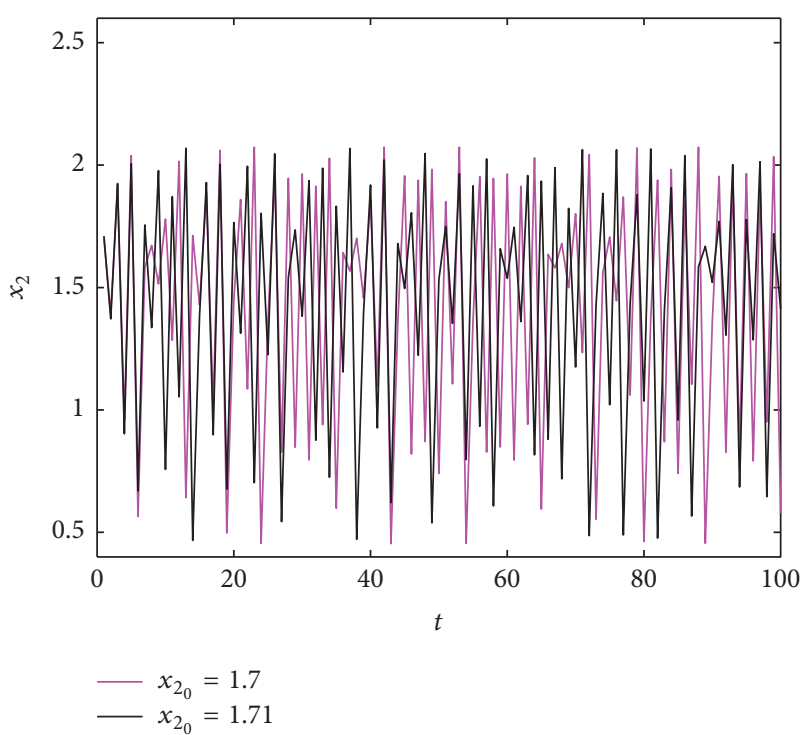

(a)

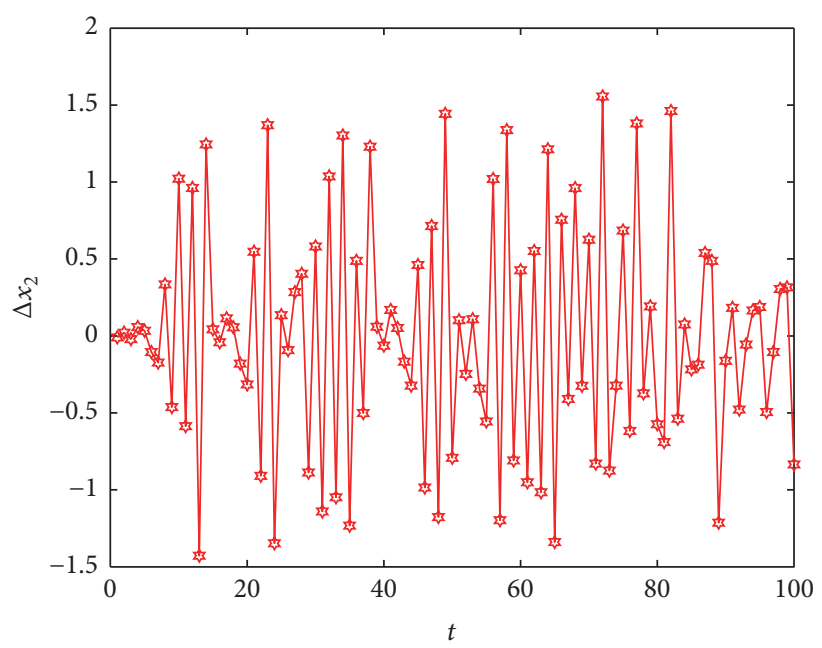

(b)

FIgURE 14: The two orbits and difference of $x_{2}$ coordinates for initial points $(1.4,1.7)$ and $(1.4,1.71)$ and $\left(\alpha_{1}=0.42, \alpha_{2}=1.34\right)$.

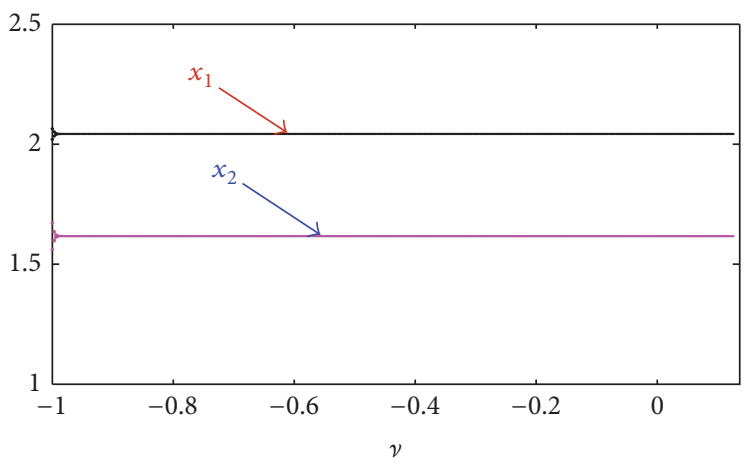

FIGURE 15: Bifurcation diagram of system (14) with $\mu \in[-1,0.1362]$, for $\left(\alpha_{1}=1.39, \alpha_{2}=0.36\right)$.

\section{Conflicts of Interest}

The authors declare that they have no conflicts of interest.

\section{Acknowledgments}

Thanks are due to Professor Ma Junhai for his guidance and advice. The research was supported by the National Natural Science Foundation of China (Grant no. 61273231).

\section{References}

[1] P. Dasgupta and E. Maskin, "The existence of equilibrium in discontinuous economic games. I. Theory," The Review of Economic Studies, vol. 53, no. 1, pp. 1-26, 1986.

[2] C. Aspremont and A. Jacquemin, "Cooperative and noncooperative R\&D in duopoly with spillovers," American Economic Review, vol. 78, no. 5, pp. 1133-1137, 1988.

[3] H. Gersbach and A. Schmutzler, "External spillovers, internal spillovers and the geography of production and innovation,"
Regional Science \& Urban Economics, vol. 29, no. 6, pp. 679-696, 1999.

[4] G.-I. Bischi and F. Lamantia, "Nonlinear duopoly games with positive cost externalities due to spillover effects," Chaos, Solitons \& Fractals, vol. 13, no. 4, pp. 701-721, 2002.

[5] I. Milstein and A. Tishler, "R\&D wars and the effects of innovation on the success and survivability of firms in oligopoly markets," International Journal of Industrial Organization, vol. 27, no. 4, pp. 519-531, 2009.

[6] M.-L. Petit and F. Sanna-Randaccio, "Endogenous R\&D and foreign direct investment in international oligopolies," International Journal of Industrial Organization, vol. 18, no. 2, pp. 339$367,2000$.

[7] S. Luckraz, "R\&D games in a Cournot duopoly with isoelastic demand functions: a comment," Economic Modelling, vol. 28, no. 6, pp. 2873-2876, 2011.

[8] S. Luckraz, "On innovation cycles in a finite discrete R\&D game," Economic Modelling, vol. 30, no. 1, pp. 510-513, 2013.

[9] L. A. Grunfeld, "Multinational production, absorptive capacity, and endogenous RD spillovers," Review of International Economics, vol. 14, no. 5, pp. 922-940, 2006. 
[10] L. Fanti, L. Gori, and M. Sodini, "Nonlinear dynamics in a Cournot duopoly with relative profit delegation," Chaos, Solitons \& Fractals, vol. 45, no. 12, pp. 1469-1478, 2012.

[11] J. Ma and Z. Guo, "The parameter basin and complex of dynamic game with estimation and two-stage consideration," Applied Mathematics and Computation, vol. 248, pp. 131-142, 2014.

[12] J.-H. Ma and W.-Z. Ji, "Complexity of repeated game model in electric power triopoly," Chaos, Solitons \& Fractals, vol. 40, no. 4, pp. 1735-1740, 2009.

[13] J. Ma and H. Tu, "Complexity of a duopoly game in the electricity market with delayed bounded rationality," Discrete Dynamics in Nature and Society, vol. 2012, Article ID 698270, 2012.

[14] F. Wu and J. Ma, "The chaos dynamic of multiproduct Cournot duopoly game with managerial delegation," Discrete Dynamics in Nature and Society, Article ID 206961, 10 pages, 2014.

[15] A. Matsumoto and Y. Nonaka, "Statistical dynamics in a chaotic cournot model with complementary goods," Journal of Economic Behavior \& Organization, vol. 61, no. 4, pp. 769-783, 2006.

[16] F. Tramontana, "Heterogeneous duopoly with isoelastic demand function," Economic Modelling, vol. 27, no. 1, pp. 350-357, 2010.

[17] F. Tramontana and A. A. Elsadany, "Heterogeneous triopoly game with isoelastic demand function," Nonlinear Dynamics, vol. 68, no. 1-2, pp. 187-193, 2012.

[18] H.-X. Yao, L. Shi, and H. Xi, "Analysis of triopoly game with isoelastic demand function and heterogeneous players," Discrete Dynamics in Nature and Society, Article ID 280824, 16 pages, 2012.

[19] F. Chen, J. H. Ma, and X. Q. Chen, "The study of dynamic process of the triopoly games in Chinese $3 \mathrm{G}$ telecommunication market," Chaos, Solitons \& Fractals, vol. 42, no. 3, pp. 1542-1551, 2009.

[20] Y. Guo and J. Ma, "Research on game model and complexity of retailer collecting and selling in closed-loop supply chain," Applied Mathematical Modelling: Simulation and Computation for Engineering and Environmental Systems, vol. 37, no. 7, pp. 5047-5058, 2013.

[21] J. Ma and Q. Li, "The complex dynamics of BertrandStackelberg pricing models in a risk-averse supply chain," Discrete Dynamics in Nature and Society, Article ID 749769, 14 pages, 2014.

[22] Z. Sun and J. Ma, "Complexity of triopoly price game in Chinese cold rolled steel market," Nonlinear Dynamics, vol. 67, no. 3, pp. 2001-2008, 2012.

[23] J. Ma and X. Pu, "The research on cournot-bertrand duopoly model with heterogeneous goods and its complex characteristics," Nonlinear Dynamics, vol. 72, no. 4, pp. 895-903, 2013.

[24] J. Ma and L. Xie, "The comparison and complex analysis on dual-channel supply chain under different channel power structures and uncertain demand," Nonlinear Dynamics, vol. 83, no. 3, pp. 1379-1393, 2016.

[25] J. Ma, Q. Zhang, and Q. Gao, "Stability of a three-species symbiosis model with delays," Nonlinear Dynamics, vol. 67, no. 1, pp. 567-572, 2012.

[26] J. Ma and Y. Liu, "Exact solutions for a generalized nonlinear fractional Fokker-Planck equation," Nonlinear Analysis: Real World Applications, vol. 11, no. 1, pp. 515-521, 2010.
[27] $\mathrm{H} . \mathrm{Tu}$ and $\mathrm{X}$. Wang, "Research on a dynamic master-slave cournot triopoly game model with bounded rational rule and its control," Mathematical Problems in Engineering, Article ID 2353909, 11 pages, 2016.

[28] R. Hu, Q. Chen, and Q. Wang, "Complexity analysis of dynamic $\mathrm{RD}$ competition in duopoly," Journal of Industrial Engineering and Engineering Management, vol. 25, no. 2, pp. 118-123, 2011.

[29] Z. Sheng, Y. Li, and G. Chen, "Global complexity of RD dynamic competition model," Journal of Management Sciences in China, vol. 9, no. 3, pp. 1-9, 2006.

[30] T. Li and J. Ma, "The complex dynamics of R\&D competition models of three oligarchs with heterogeneous players," Nonlinear Dynamics, vol. 74, no. 1-2, pp. 45-54, 2013.

[31] H. Xu, G. Wang, and S. Chen, "Controlling chaos by a modified straight-line stabilization method," The European Physical Journal B, vol. 22, no. 1, pp. 65-69, 2001.

[32] L. Yang, Z. Liu, and J.-M. Mao, "Controlling hyperchaos," Physical Review Letters, vol. 84, no. 1, pp. 67-70, 2000. 


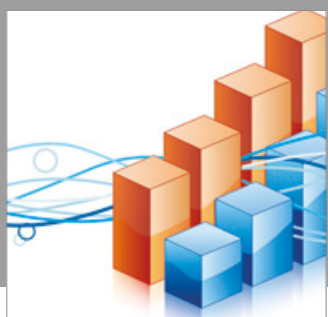

Advances in

Operations Research

vatersals

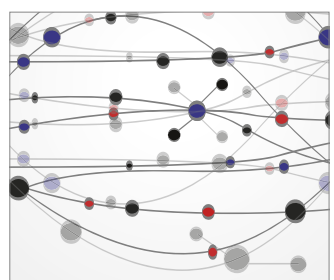

\section{The Scientific} World Journal
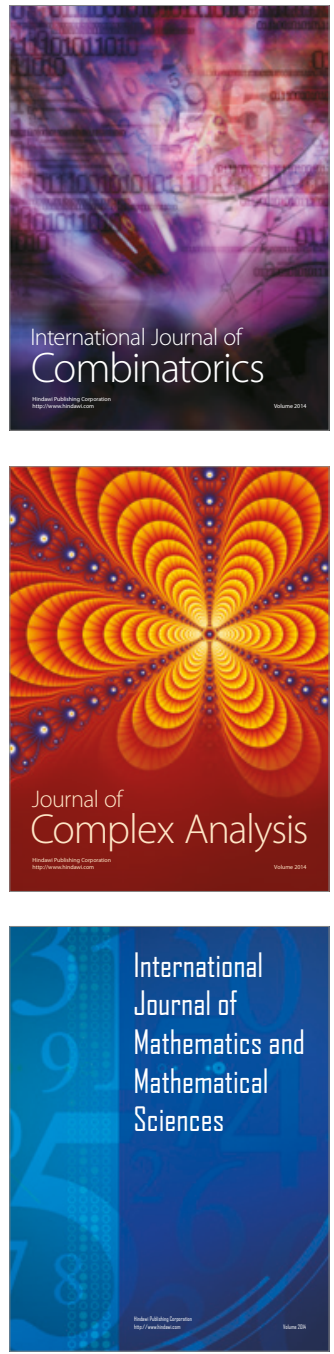
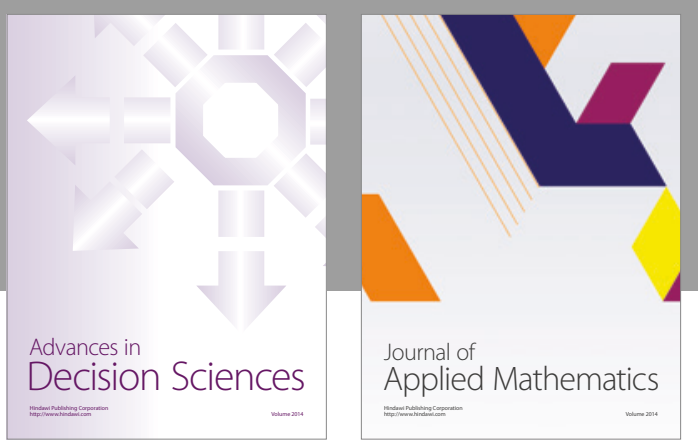

Algebra

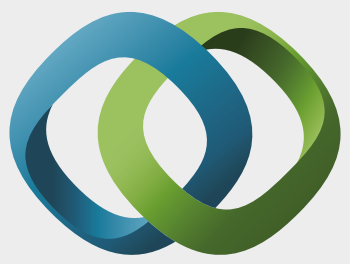

\section{Hindawi}

Submit your manuscripts at

https://www.hindawi.com
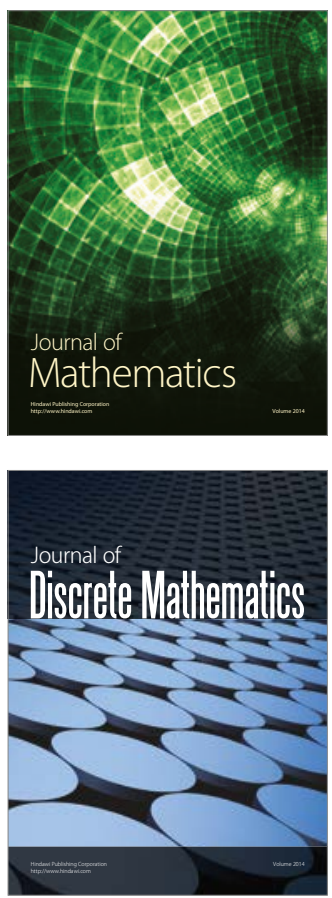

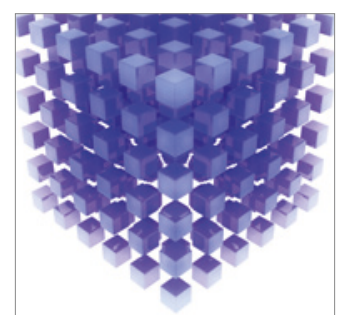

Mathematical Problems in Engineering
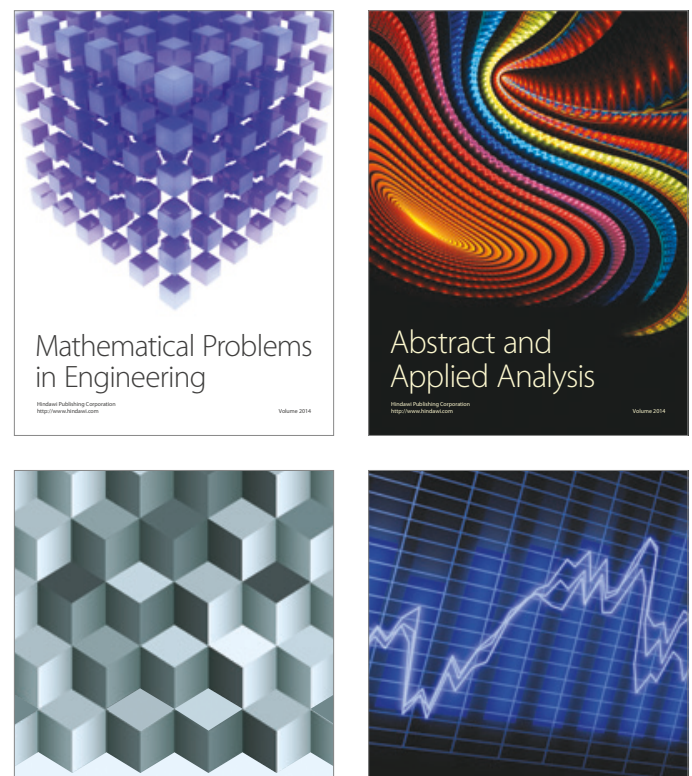

Journal of

Function Spaces

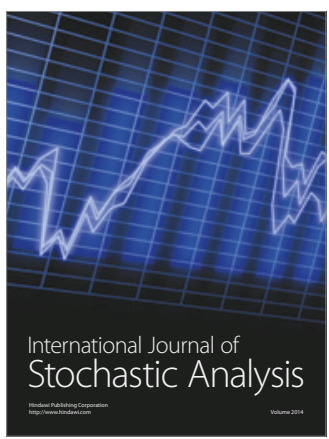

Probability and Statistics
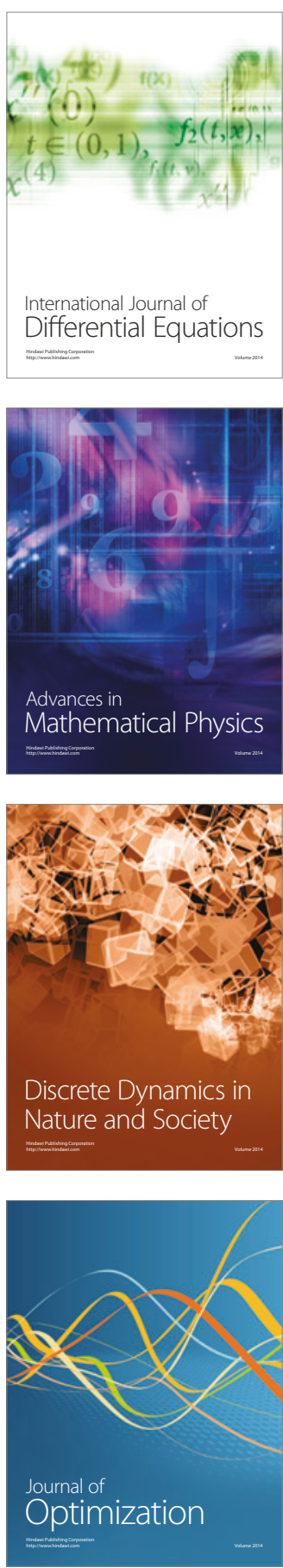